7. Астафьева E. С. Проблемы расчета себестоимости и формирования стоимости платных образовательных услуг // Территория новых возможностей. Вестн. Влади- вост. гос. ун-та экономики и сервиса. 2012. № 1. С. 164-173.

8. Гори А. Нематериальное знание, стоимость и капитал. М. : Изд. дом Гос. ун-та - ВШЭ, 2010. 208 с.

Образец для цитирования:

Тугушева Р. Р. Проявление фиктивности в интеллектуальных товарах в экономике знаний // Изв. Сарат. ун-та. Нов. сер. Сер. Экономика. Управление. Право. 2016. Т. 16, вып. 4. С. 390-394. DOI: 10.18500/1994-2540-2016-164-390-394.

\section{Demonstration of Fictitious in Intelligent Goods at the Economy Knowledge}

\section{R. R. Tugusheva}

Saratov State University,

83, Astrakhanskaya str., Saratov, 410012, Russia

E-mail: ryasimya.tugusheva@mail.ru

Introduction.Changes in the economic system at the present stage first of all are bound to the changes imposed to the workforce. Currently, the intellectual work, which is characterized by cognition becomes more significant in industrial sector. In this connection, the importance of increased intangible goods, one of which is an intellectual goods run high. The intelligent goods have specific properties, one of which is fictitious. Theoretical analysis. The article contains various definitions of what «knowledge» and «information» are. It also contains the analysis of the features of the process of production of intellectual goods, in the creation of which the main resource is knowledge. Besides, the article contains the main approaches to the definition of «fictitious goods». Results. It is noted that there is a gap between value and the value of intellectual goods. Also noted that while determining the value of these goods comes up some difficulties with assessing the labor by their production. Based on an analysis of different approaches to the concept of «fictitious goods» defined that knowledge has the properties of fictitious and the intellectual goods is a fictitious goods, and that is its main feature.

Key words: knowledge, information, intellectual product, intellectual goods, fictitious goods.

\section{References}

1. Sovremennyi tolkovyi slovar' russkogo yazyka [Modern Dictionary of Russian language. Ans. ed. S. A. Kuz- netsova]. St. Petersburg, Norint Publ., 2001. 960 p.

2. Khodzhson Dzh. Sotsial'no-ekonomicheskie posledstviya progressa znaniy i narastaniya slozhnosti [The socioeconomic consequences of the progress of knowledge and the increasing complexity]. Voprosy ekonomiki, 2001, no. 8, pp. 32-45.

3. Crawford R. In the Era of Human Capital: The Emergence of Talent, Intelligence and Knowledge as the Worldwide Economic Force and Means to Managers and Investors. New York, Harper Business, 1991. 154 p.

4. Polan'i K. Samoreguliruyuschiy rynok i fiktivnye tovary: trud, zemlya i kapital [The self-regulating market and fi ctitious goods: work, earth and capital]. Thesis, 1993, iss. 2, pp. 10-18.

5. Isayev A. A. Fiktivnaya ekonomika [Fictitious economy]. Vladivostok, VGUES Publ., 2009. 160 p.

6. Veltz P. La nouvelle revolution industrielle. Revue de MAUSS, 2001, no. 18, pp. 67-70.

7. Astaf'yeva E. S. Problemy raschota sebestoimosti i formirovaniya stoimosti platnykh obrazovatel'nykh uslug [Calculation of cost issues and the formation of the cost of paid educational services]. Territoriya novykh vozmozhnostey. Vestnik Vladivostokskogo gosudarstvennogo universiteta ekonomiki i servisa [The territory of new opportunities. The Herald of Vladivostok State University of Economics and Service], 2012, no. 1, pp. 164-173.

8. Gorts A. Nematerial'noye znanie, stoimost' $i$ capital [Non-material knowledge, cost and capital]. Moscow, Publ. House State University - SHE, 2010. 208 p.

Please cite this article in press as:

Tugusheva R. R. Demonstration of Fictitious in Intelligent Goods at the Economy Knowledge. Izv. Saratov Univ. (N.S.), Ser. Economics. Management. Law, 2016, vol. 16, iss. 4, pp. 390-394 (in Russian). DOI: 10.18500/1994-2540-2016-16-4-390-394.

УДК 338

АНАЛИЗ ЭФФЕКТИВНОСТИ ПРИМЕНЕНИЯ ПОЛИТИКИ ИНФЛЯЦИОННОГО ТАРГЕТИРОВАНИЯ В РОССИЙСКОЙ ЭКОНОМИКЕ

\section{Ю. Ю. Савина}

аспирант кафедры экономической теории и национальной экономики, Саратовский национальный исследовательский государственный университет имени Н. Г. Чернышевского

E-mail: Juliana070587@rambler.ru

Введение. Одним из ключевых направлений развития России является реализация денежно-кредитной политики, способной при наличии прозрачного и понятного целеполагания обеспечить достижение первоочередных задач монетарного регулирования. Теоретический анализ. Исследование проводится на основе анализа основных показателей экономического развития страны, опыта монетарного регулирования зарубежных стран, а также оценки возможностей и проблем реализации политики, выбранной Центральным банком, в условиях открытости экономики. Результаты. Проведенный в статье анализ позволяет 
определить степень влияния денежно-кредитной политики на инфляцию в нашей стране, изменения, которые создают новые возможности для экономического развития. Выводы. По результатам проведенного анализа делается вывод о необходимости замены практики инфляционного таргетирования более современными методами противодействия инфляции.

Ключевые слова: инфляция, таргетирование, количественная теория денег.

DOI: 10.18500/1994-2540-2016-16-4-394-399

\section{Введение}

Наша страна стоит на пути формирования новых приоритетов, новых подходов к решению задач, возникающих перед Россией.

Создание комфортных условий для инвесторов и бизнеса начинается с обеспечения макроэкономической стабильности. Низкий уровень инфляции и сбалансированный бюджет остаются приоритетами для устойчивого развития страны, важным условием роста благосостояния граждан, обеспечения доступности кредитов для бизнеса, предсказуемости экономического развития.

Одним из ключевых направлений развития России стала разработка режима денежно-кредитной политики, способного при наличии прозрачного и понятного целеполагания обеспечить достижение первоочередных задач монетарного регулирования. Первостепенная задача Центрального банка России при этом заключается в нахождении уровня денежной базы в экономике, который способствовал бы экономическому развитию страны.

\section{Теоретический анализ}

Эффективное применение различных инструментов денежно-кредитной политики должно обеспечивать достижение целей в различных временных интервалах. Стратегической целью денежно-кредитной политики в России на настоящий момент является достижение стабильности цен, поддержание и стимулирование экономического роста во всех секторах экономики, и прежде всего в реальном, высокая занятость, низкие темпы инфляции.

В современной экономической литературе по-прежнему остаются нерешенными проблема выбора между следованием определенным правилам и свободой действий Центрального банка, проблема нахождения правильного соотношения целей и инструментов денежно-кредитной политики. Дискуссия по названным проблемам была начата еще в работах М. Туган-Барановского, Й. Шумпетера, Дж. М. Кейнса, М. Фридмана. Ключевой проблемой был выбор оптимальной денежно-кредитной политики, оказывающей влияние как на инвестиционную, так и на экономическую политику в конкретных экономических условиях.
Все вышеперечисленные авторы в своих работах приходили к мысли о том, что государство должно формировать активный механизм регулирования финансово-кредитной сферы, соответствующий этапу экономического развития страны, а также к идеям о необходимости государственного регулирования всей национальной денежной системы и межгосударственного согласования валютных и кредитных политик стран, имеющих устойчивую тенденцию к углублению и развитию взаимного товарооборота.

По мнению М. И. Туган-Барановского, денежная единица с колеблющейся ценностью «есть великое хозяйственное зло, крайне задерживающее развитие производительных сил страны <...> Только при наличности устойчивой валюты можно рассчитывать на широкий приток в нашу страну иностранных капиталов, без чего невозможно быстрое развитие наших производительных сил $<\ldots>$ Активная валютная политика должна быть признана одной из важнейших составных частей правильной экономической программы. Строение вексельного курса не должно быть предоставлено случайным биржевым воздействиям, но взято в руки государства. Власть государства в этой области ограничена хозяйственными силами...» [1, c. 412-413, 419].

О решающей роли денежного фактора в экономической политике заговорили в 70-е гг. прошлого века, хотя интерес к нему возник гораздо раньше, когда монетаристы выдвинули лозунг «Деньги имеют значение» (Money matters), ставший символом их учения.

Американские экономисты включили денежные агрегаты в свои эконометрические модели, а центральные банки крупнейших стран переориентировались с таргетирования валютного курса на таргетирование денежных агрегатов. Вскоре крупнейшие страны Европы проводили таргетирование и валютного курса, и денежного предложения, которое затем было заменено на инфляционное таргетирование. Результаты применения режима инфляционного таргетирования в развитых странах оказались выше, чем в странах с развивающейся экономикой, учитывая, что в любой из фаз экономического цикла применение политики таргетирования имело свои особенности.

В настоящее время одной из популярных монетарных стратегий является инфляционное таргетирование.

Под инфляционным третированием в экономической науке принято понимать целеполагание, при котором денежные власти берут на себя обязательство достичь определенного целевого показателя по инфляции. Долгое время в западной экономической науке рассматривался тезис о чисто денежном характере инфляции. До настоящего 
времени среди ученых идет спор о природе инфляции и, следовательно, о приоритетности мер ее подавления. Для выдающегося русского ученого, экономиста, историка М. И. Туган-Барановского этот вопрос был абсолютно ясным, поскольку он усматривал первопричины инфляции в нарушении воспроизводственного процесса, в деформации структурного равновесия в хозяйстве.

Подробный историографический анализ феномена инфляции и механизмов его регулирования предлагает монетаристская теория Милтона Фридмана, его работа «Количественная теория денег» - это теория спроса на деньги, а не теория производства, или денежного дохода, или уровня цен.

Проблема инфляции занимала одно из центральных мест в монетаристском труде, где зависимость между изменением количества денег и уровнем цен рассматривалась как основная закономерность. Ключевая мысль монетаристской теории инфляции сводилась к тому, что важнейшая причина усиления инфляционного процесса состоит в более быстром росте номинальной денежной массы по сравнению с ростом продукта.

Развитие монетаристских взглядов по вопросам инфляции проходило в два этапа. И после первого этапа выявления механизма развития инфляции внимание было обращено на проблему связи инфляции и безработицы. Данный анализ относился к так называемому внутреннему монетаризму [2].

На протяжении двух десятилетий во всем мире нарастал интерес к исследованиям в области влияния денежного предложения, и происходила перестройка денежно-кредитной сферы, сопровождающаяся эволюцией целей и приоритетов центральных банков. Сначала таргетирование инфляции использовалось исключительно в развитых странах, а развивающиеся страны практически повсеместно использовали режим фиксированного обменного курса. Однако уже в конце 1990-х гг. данный режим начали использовать развивающиеся страны и страны с переходной экономикой [3].

Доминирование монетаристского подхода в экономической науке в течение последних лет оказало значительное влияние на понимание инфляции и в России. Инфляция считается серьезной социально-экономической проблемой, влияние которой на экономическое развитие страны весьма значительно и неоднозначно, она крайне негативна для экономики и социальной сферы, поскольку дезорганизует воспроизводство. Однако попытка объяснить современную динамику цен действием одних лишь денежных факторов имела много слабых мест, так как трактовка о чисто денежной природе инфляции неверно отражает инфляционные процессы.
Ранее денежными властями России проводился контроль валютного курса, но не оказывалось прямого воздействия на инфляцию. При этом чиновники и экономисты уже неоднократно указывали на то, что в целях формирования долгосрочных ориентиров для бизнеса полезнее контролировать инфляцию. И таргетирование валютного курса, и инфляционное таргетирование направлены на макроэкономическую стабилизацию и, следовательно, повышение уверенности в завтрашнем дне для бизнеса и домохозяйств. Однако таргетирование инфляции - инструмент, оказывающий более сильное влияние на настроение бизнеса и его инвестиционные планы. Валютный курс краткосрочный показатель, инфляция - средне- и долгосрочный. Таргетирование инфляции дает возможность установить смотрящий в будущее ориентир, что при успешной реализации выражается в большей предсказуемости. В год, предшествующий введению режима таргетирования, проект основных направлений финансово-кредитной программы ЦБ РФ определял целевой ориентир по инфляции на 2013 г. в 5-6\%, на 2014 2015 гг. - 4-5\% [4].

В большинстве стран в качестве показателя при оценке инфляции используется индекс потребительских цен - показатель, учитывающий цены на определенные группы товаров и услуг. Некоторые страны, чтобы избежать влияния шоков, используют для таргетирования базовую инфляцию, в которой не учитываются цены на продукты питания. Говоря о методологических аспектах таргетирования инфляции в России, нужно отметить, что на сегодняшний день выбор индекса потребительских цен в качестве индикатора инфляции Центральным банком РФ обусловлен тем, что он лучше характеризует изменение стоимости жизни и его динамика влияет на формирование инфляционных ожиданий субъектов экономики.

Преодоление инфляции является условием нормального экономического развития. Но снижение инфляции не дает гарантии автоматического подъема производства. Процессы снижения инфляции и подъема производства должны идти одновременно.

Высокая инфляция стала одной из основных проблем России вследствие санкций и политической ситуации в мире. В этой связи смещение акцентов внутренней экономической политики в целом и денежно-кредитной политики в частности на режим таргетирования инфляции, получивший за последние два десятилетия широкое распространение в мировой практике, вышло на первый план.

Параллельно с инфляционным таргетированием происходит отказ от целевых показателей по другим экономическим показателям, таким как 
заработная плата, уровень занятости, валютный курс, поскольку в условиях стремления к достижению сразу нескольких целей участники рынка не знают, какой из них в случае ухудшения ситуации будет отдано предпочтение [5].

В плане Центрального банка РФ при результативных показателях годовой инфляции в августе 2015 г. в 15,8\%, а в феврале 2016 г. 8,1\% обозначена цель 2017 г. - 4,0\% (рисунок).

Основа для целевого показателя инфляции была заложена задолго до его введения, этому предшествовал этап прогнозирования. Установка инфляционного таргета - это совместная инициа- тива правительства и Центрального банка, так как последний не может взять на себя обязательство самостоятельного перевода экономики в режим инфляционного таргетирования. Определение и установка целевого ориентира инфляции включает: выбор типа индекса цен; постановку цели с точки зрения уровня цен или ставки инфляции; расчет динамики предстоящей инфляции; формулировку инфляционной цели. Естественно, что таргет будет меняться из года в год. Через равные промежутки времени, после сбора значимой информации, процедура повторяется, и к реализации принимается новый план [6].

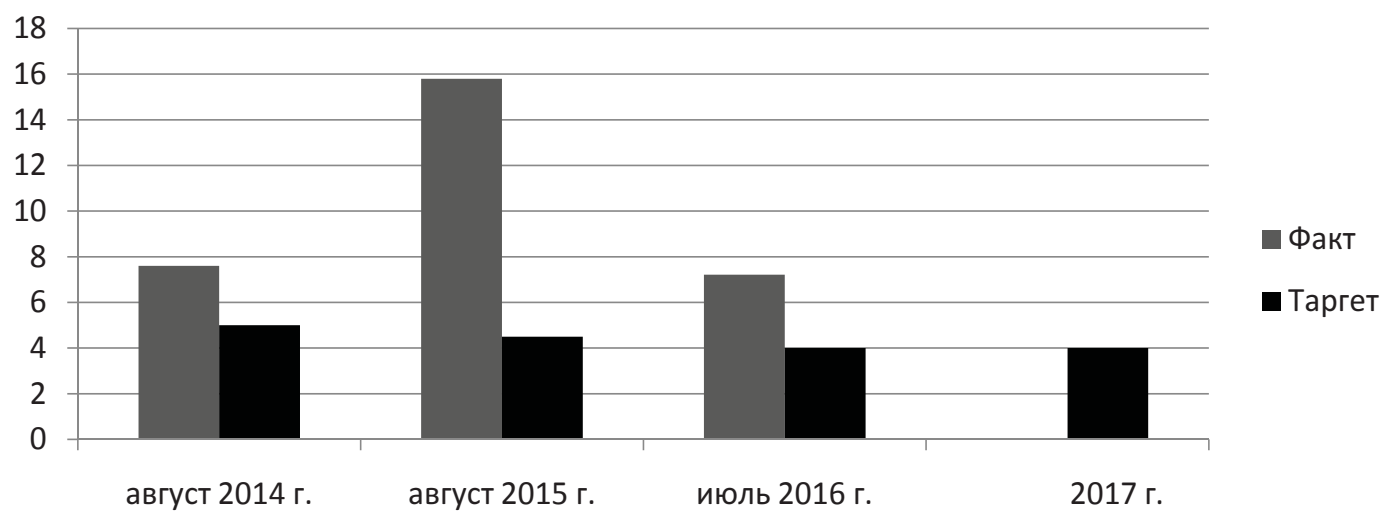

Результаты применения политики таргетирования инфляции в России 2014-2017 гг., \%

Учитывая вышеназванный целевой ориентир инфляции, можно говорить о нереалистично низком значении, что привело к замедлению экономического роста. В случае более высокого таргета политика Центрального банка и последствия этой политики были бы более благоприятны для экономического роста.

Инфляционное таргетирование в России является непростой задачей, так как российская экономика характеризуется частыми экономическими шоками, которые сводят на нет любое планирование. В разные периоды на инфляцию влияет не только денежно-кредитная политика, но и другие факторы. Государство вынужденно одновременно поддерживать доходы населения, низкую инфляцию, стабильный курс рубля, рост ВВП и восстанавливать разрушенную банковскую систему. В то время как больше половины из этих целей противоречат друг другу. На фоне нового снижения нефтяных цен увеличились риски ускорения инфляции. Ухудшение ситуации на мировых сырьевых рынках требует дальнейшей адаптации российской экономики.

Выбор целевого ориентира инфляции является итогом расчета нескольких вариантов развития событий. Финансовые и кредитные структуры формируют экономическую среду для хозяйствующих субъектов и населения. Для инфляционного таргетирования важна сама технология расчета ориентиров инфляции. Реализуемая в России денежно-кредитная политика в долгосрочной перспективе связана с административным регулированием и государственным контролем цен, приближением цен на отечественную продукцию к уровню цен на аналогичные импортные товары.

Чем же обусловлен выбор стратегии? Инфляционное таргетирование - это алгоритм решения задач оптимизации путем выработки системы решений, используемый Центральным банком. При переходе от высокой инфляции к низкой трудно предсказать скорость денежного обращения. Для эффективной реализации инфляционного таргетирования требуется оценка скорости обращения денег как минимум на год вперед при неизвестной функции спроса на деньги. Обычно эту проблему решают исходя из постоянной или даже увеличивающейся скорости оборота денег, но это нелогично.

\section{Результаты}

Проведенный в статье анализ позволяет определить степень влияния денежно-кредитной политики на инфляцию в нашей стране, изменения, которые создают новые возможности для экономического развития.

По итогам 2014-2015 гг. можно сделать вывод, что инфляционное таргетирование не стало 
эффективным инструментом достижения экономической стабильности. Особенности механизмов определили специфику и результаты. Стало очевидно, что это не единственный возможный путь развития для денежно-кредитной политики. Проводимая денежно-кредитная политика под предлогом перехода к таргетированию инфляции свелась к отказу от использования валютных ограничений и ключевой ставке. В условиях полной открытости валютно-финансового рынка повышение процентных ставок не сработало на снижение инфляции и стабилизацию курса рубля. Манипулирующие финансовым рынком спекулянты получали многократно более высокую норму прибыли, позволяющую им привлекать кредиты и после повышения ключевой ставки. Своей политикой Банк России стимулировал валютные спекуляции в ущерб реальному сектору и опаздывал с принятием мер, адекватным внешним и внутренним шокам, несмотря на то, что кредитно-денежная политика в России, как и в любой цивилизованной стране, направлена на обеспечение эффективного инвестиционного процесса с большой ролью в нем инновационной составляющей.

Таким образом, не были выполнены основные требования для введения режима, а именно: институциональная независимость, эффективная структура экономики, развитая финансовая система.

Для эффективности использования данного инструмента нужна база, которой на момент введения режима не было. Режим инфляционного таргетирования оказался намного более требовательным к институциональной среде, чем другие режимы денежно-кредитной политики. Хотя в мировой практике отмечается, что улучшение институциональной среды происходило не до, а после введения данного режима.

Кроме того, инфляция определяется во многом нестабильным состоянием на мировых рынках, что неподвластно российскому правительству. Необходима разработка новой денежно-кредитной политики, которая может заключаться в выборе показателей - например, не индекс, а базовый индекс потребительских цен.

Цена, которую мы платим за стремление снизить инфляцию на несколько процентов без учета последствий для других показателей, может быть слишком высокой - это остановка экономического роста.

Результаты таргетирования оказывают значительное влияние для объяснения прошлых результатов и мотивируют текущие решения, как правило, со ссылкой на опубликованные условные прогнозы инфляции.

\section{Выводы}

Несмотря на то, что в ближайшее время число стран, использующих режим инфляционного таргетирования, будет расти, в нынешней российской реальности, в условиях догоняющего развития, необходимости резкого роста инвестиций, концентрация ЦБ на одной лишь инфляции без учета ее влияния на другие показатели способна привести к негативным последствиям, так как практически полностью игнорируются аспекты промышленного и экономического роста. Очень важна четкая среднесрочная стратегия.

Важно намечать выполнимые ориентиры с учетом конъюнктуры, проводить политику достижения целей, корректировать тактику с учетом рисков. Темпы инфляции не дают достоверной картины российской экономики и возникших диспропорций. Пока регулятор нацелен на переход к таргетированию инфляции, и остается только надеяться на то, что со временем весь механизм таргетирования будет освоен. Денежно-кредитная политика должна не сводиться к подавлению цен «любой ценой», а обеспечивать повышение экономической активности, доходов граждан. В этой связи перспективнее говорить о необходимости стабилизации циклических изменений ВВП и введении таргетирования ВВП, который менее зависим от потрясений. Следует выстроить механизм управления рыночными ожиданиями, так как уверенность в будущем влечет за собой приток капитала и рост инвестиций.

\section{Список литературы}

1. Туган-Барановский М. И. Бумажные деньги и металл // Туган-Барановский М. И. Экономические очерки. М. : РОССПЭН, 1998. 537 с.

2. Лиференко Ю. В. Новый взгляд на теорию и практику инфляционного таргетирования // Финансы и кредит. 2014. № 8(584). C. 36-47.

3. Богданович Н. Ю. Перспективы перехода к режиму таргетирования инфляции в РФ // Вестн. СГСЭУ. 2009. № 5 (29). С. 21-26.

4. Центральный Банк Российской Федерации : [сайт]. URL: http://www.cbr.ru (дата обращения: 11.09.2016).

5. Моисеев С. Р. Инфляционное таргетирование : международный опыт и российские перспективы // Вопр. экономики. 2000. № 9. С. 88-105.

6. Юдаева К. В. О возможностях, целях и механизмах денежно-кредитной политики в текущей ситуации // Вопр. экономики. 2014. № 9. С. 4-12.

\section{Образец для цитирования:}

Савина Ю. Ю. Анализ эффективности применения политики инфляционного таргетирования в российской экономике // Изв. Сарат. ун-та. Нов. сер. Сер. Экономика. Управление. Право. 2016. Т. 16, вып. 4. С. $394-399$. DOI: 10.18500/1994-2540-2016-16-4-394-399. 
Ekonomicheskie ocherki [Economic essays]. Moscow, ROSSPEN Publ., 1998. 537 p.

2. Liferenko Yu. V. Novyi vzglyad na teoriyu i praktiku inflyatsionnogo targetirovaniya [A new look at the theory and practice of inflation targeting]. Finansy $i$ kredit [Finances and credit], 2014, no. 8 (584), pp. 36-47.

3. Bogdanovic N. Yu. Perspektivy perekhoda k rezhimu targetirovaniya inflyatsii v RF [Prospects for the transition to inflation targeting in Russia]. Vestnik Saratovskogo gosudarstvennogo sotsial'no-ekonomicheskogo universiteta [Vestnik of Saratov State Socio-Economic University], 2009, no. 5, (29), pp. 21-26.

4. Tsentral'nyi Bank Rossiiskoi Federatsii (The Central Bank of the Russian Federation. Site). Available at: http:// www.cbr.ru (accessed 11 September 2016).

5. Moiseev S. R. Inflyatsionnoe targetirovanie: mezhdunarodnyi opyt i rossiiskie perspektivy [Inflation Targeting: International Experience and Russian Prospects]. Voprosy economiki, 2000, no. 9, pp. 88-105.

6. Yudaeva K. V. O vozmozhnostyakh, tselyakh i mekhanizmakh denezhno-kreditnoi politiki v tekuschei situatsii [On the possibilities of, and mechanisms for monetary policy in the current situation]. Voprosy economiki, 2014, no. 9, pp. 4-12.

Please cite this article in press as:

Savina Yu. Yu. Analysis of the Inflation Targeting Policy Effectiveness in the Russian Economy. Izv. Saratov Univ. (N.S.), Ser. Economics. Management. Law, 2016, vol. 16, iss. 4, pp. 394-399 (in Russian). DOI: 10.18500/1994-2540-2016-16-4-394-399.

\section{ИНСТИТУЦИОНАЛЬНЫЕ ФАКТОРЫ КОНКУРЕНТОСПОСОБНОСТИ ОРГАНИЗАЦИИ: ПОНЯТИЕ, КЛАССИФИКАЦИЯ, ЗАКОНОМЕРНОСТИ ВЗАИМОСВЯЗЕЙ}

\author{
А. Е. Рудь \\ аспирант кафедры экономики и таможенного дела, \\ Поволжский институт управления имени П. А. Столыпина - \\ филиал РАНХиГС при Президенте РФ, Саратов \\ E-mail: arud_91@mail.ru
}

Введение. Повышение конкурентоспособности организаций в условиях внешних вызовов и экономического кризиса является одним из основных направлений современной экономической стратегии государства. Практика развитых стран показывает, что определяющим условием повышения конкурентоспособности организаций является эффективное взаимодействие между различными институтами. Отсюда проблемы взаимосвязи между разными институциональными факторами и их влияния на конкурентоспособность организаций являются весьма актуальными. Теоретический анализ. В статье рассматриваются различные подходы к выделению приоритетных институциональных факторов, влияющих на конкурентоспособность организаций. Результаты. Предложены авторская трактовка понятия «институциональные факторы», авторская классификация институциональных факторов, включающая в себя обеспечивающие и блокирующие факторы, выявлены закономерности взаимосвязей между ними и показано их влияние на конкурентоспособность организаций.

Ключевые слова: конкурентоспособность организации, институциональные факторы, обеспечивающие институциональные факторы, блокирующие институциональные факторы, дуализм, неравновесная система, доминантность.

\section{DOI: 10.18500/1994-2540-2016-16-4-399-403}

\section{Введение}

Повышение конкурентоспособности организаций в условиях внешних вызовов и экономического кризиса является одним из основных направлений современной экономической стратегии государства. Практика развитых стран показывает, что определяющим условием повышения 